\title{
Short-Term Capital Flows in China: Trend, Determinants and Policy Implications
}

\author{
Haizhen Yang ${ }^{1,2}$, Yanping Zhao ${ }^{1}$, and Yujing $\mathrm{Ze}^{1}$ \\ ${ }^{1}$ Graduate University of Chinese Academy of Sciences, \\ Beijing 100190, China \\ ${ }^{2}$ Research Centre on Fictitious Economy and Data Science, CAS, \\ Beijing 100190, China \\ haizheny@gucas.ac.cn
}

\begin{abstract}
The volatility of international capital flows have further increased both in volume and speed since the outbreak of subprime crisis originating from America. Orientation of international capital flows blurred because of the downward expectation on the growth rate in main countries. Since the shortterm capital flow has gradually become an important part of international capital flow in China in decade, the volatility of short-term capital flows may affect the development of Chinese economy severely. A structural model-VECM was build to explore the determinants of net flows of short-term capital in China. The conclusions of this study were that net flows in China are largely determined by estate price, circulated stock value, expectation on exchange rate and interest rate. On that basis, some policy suggestions were proposed.
\end{abstract}

Keywords: short-term capital inflow, determinants, VECM.

\section{Introduction}

As the development of financial integration, the volatility of international capital increased both in volume and speed, which should be viewed as a mixed blessing. On one hand, the international capital flows have brought about advanced management, technology and growth potential; and on the other hand, a surge in capital flows will probably bring about some difficulties on monitoring and threat the development of economy. The financial crises have always been related to periodic international capital flows and fluctuations. Specifically, short-term international capital, with high fluctuations, may mess economy quickly. This is due to its variability, as the capital coming in quickly can flow out just as fast.

Generally speaking, a loan or investment within a period less than a year is defined as "short-term capital", while over a year is known as "long-term capital". However, with the development of financial market and the innovation of financial instruments, the line between "short-term capital" and "long-term capital" has blurred. In view of the standards adopted by Balance of Payment and the relatively strict regulation on international capital flows in China, we identify short-term capital as a combination of portfolio investments, other investment flows (except long-term loans), and the partly un-tracked implicit capital represented by errors and omissions. 
Figure 1 shows both the absolute amount of capital inflows and outflows has surged in decade, the ratios of short-term inflows to the total private inflows have greatly increased while the ratios of short-term outflows to the total private outflows are stable. CNY has appreciated gradually accompanying with a boom in housing and stock market since the exchange rate reform in 2005. In the mean while, short-term capital flow to China is on a large scale. Inflows of short-term capital raised inflation pressure, which could influence the steady development of China.
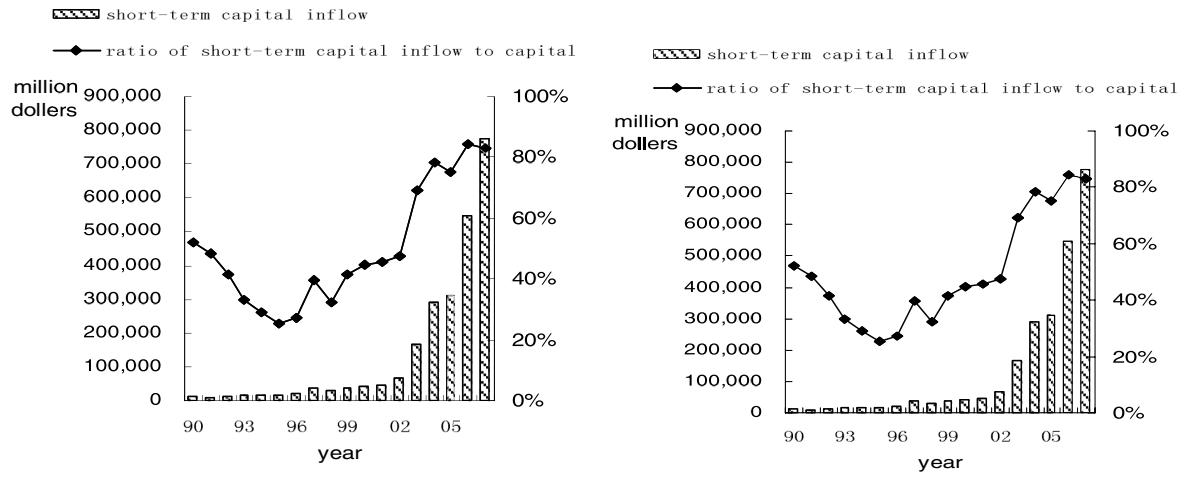

Fig. 1. Short-term capital in China

China's economy is facing new challenges in the global economy crises. Shortterm capital flow to China is under a pressure of outflow. In this circumstance, on the basis of summarize the driving causes of net flows of short-term capital; empirical study the determinants of capital flows in China in decade has significance.

\section{Literature Review}

Some studies focusing on the determinants of short-term capital flows have been achieved. Most scholars classified the factors affecting capital flows into two categories, which are "pull factors" reflecting domestic opportunity and risk, and "push factors" reflecting global change and influence. Schadler et al. [1] showed that pull factors are more important. But Chuhan et al. [2] argued that compared with domestic factors, global factors, such as a fall in US interest rates and the slow down in US production were more important or at least as important. Chuhan et al further concluded that lower international interest could explain more than $50 \%$ of the capital flowing to emerging countries. He also pointed out that compared with bond flows; equity flows were more responsive to global factors; bond flows were more responsive to a country's credit rating and the secondary-market price of debt. In-Mee Baek [3] observed that portfolio investment in Asia was dominantly pushed by investors' appetite for risk and other external factors, while in Latin American, it was pulled mainly by rapid economic growth and global factors rather than the market's risk appetite. 
Since China's accession to the WTO, the studies focus on the determinants of short-term capital flows in China was prevalent (Wang [4], Wang [5], Liu [6]). Jiang [7] identified arbitrage as the primary determinant of short-term capital flows. She also suggested that both financial innovation and development of capital markets made transactional activities remarkably convenient. Wang(2003) ${ }^{[8]}$, Liu and Wen [9] analyzed the determining factors, such as interest rate, exchange rate, and assets price employing OLS (Ordinary Least Squares)., Zhang, Pei, and Fang [10] analyzed inflows of short-term international capital employing a triple-arbitrage model. Lan and Chen [11] counted the co-integration relationship among interest rate, exchange rate expectation, and capital control, which indicated that the above-mentioned variables are highly correlated.

Previous studies have made great progress in analyzing the determinants of capital flows. However, there are still some topics need further discussions. First of all, there are few studies concerning new features of short-term capital flows surge in China after Southeastern Asian financial crisis. In addition, most studies applied multiple regression analysis, which can not reflect dynamic progress perfectly. This paper will use dynamic econometrics methods to identify the driving factors affecting short-term capital flows in China. What's more, quarterly data, rather than annual data, have been adopted to enhance the frequency of empirical testing.

\section{Determinants of Short-Term Capital Flows}

Based on Mundell-Fleming Model, which is the extension of Interest Rate Parity Theory, risk reward of arbitrage capital flows are defined as: $p=r_{d}-r_{f}-\Delta E$

Where

$P$ denotes risk reward pursued by arbitrage capital flows,

$r_{d}$ denotes domestic interest rates,

$r_{d}$ denotes foreign interest rates,

$\Delta E$ denotes static expected exchange rate.

The model indicates that the risk reward can be divided into two parts. One part is interest difference, short-term capital always flow from countries with lower interest to higher ones. Another part is reward from expected fluctuations in the exchange rate. The mechanism is that the expectation on currency appreciation brings about short-term capital inflows; correspondingly, the expectation on currency depreciation brings about outflows. In view of Mundell-Fleming Model and costs of short-term capital flows in China is high, we must consider real interest difference, which have adjusted for inflation. The fluctuations of exchange rate may be another important driving factor because the expectation on CNY's appreciation has occurred since 2002, which may induce capital flow.

Short-term capital flows may aim at the revenue on the appreciation of real assets and revenue on portfolio investment in considerate of China is undergoing the economic transform. Real estate price and circulated stock value listed on the Shenzhen and Shanghai stock markets are adopted in this study as "push factors" proxies. 
A dummy variable of policy is added in the model. China carried out reform on currency exchange rate and established a managed floating exchange rate regime in July 21 st, 2005. Henceforth, the fixed exchange rate regime became flexible and marketization of CNY exchange rate mechanism has been speeded up.

\section{Model-Building and Empirical Results}

A quarterly model was build to examine the main driving factors in view of the complexity of the short-term capital flows. Vector Error Correction Model has been chosen to ensure almost short-term fluctuations to be covered in. Furthermore, mechanisms of reclamation from short-term non-equilibrium to long-term equilibrium were analyzed.

\subsection{Data Specification}

The interval for each variable is from the first quarter in 1999 to the fourth quarter in 2007. The data on net flows of short-term capital (SCF) is taken from Balance of Payment for China in million-dollars, and the calculation formula for SCF follows the former definition of short-term capital flows in section 1 (each item uses credit side of figures).

The real interest difference between China and America is signified as RR. Threemonth deposit rate which originals from Reuters is substituted for the nominal interest rate in China, while the nominal interest rate in America is signified as yield on threemonth Treasury bill on secondary market comes from the web of Federal Reserve. The CPI in China comes from macro-economic warning system of People's Bank of China. The CPI in America comes from the web of U.S. Department of Labor. RR equals to the interest rate difference between China and America minus the CPI difference between China and America. Revenue on expected exchange rate is signified as DE, $D E=-\frac{E^{e}-E_{0}}{E_{0}} \mathrm{NDF}$ is a proxy of $E^{e}$, which comes from Reuters; $\mathrm{E}_{0}$ is spot exchange rate, which comes from the web of The University of British Columbia. Circulated stock value abbreviated as CSV, comes from database in China Economic Information Network. The values at the end of each season are selected, and then adjust to dollars according to the average exchange rate in the month. RE is housing price index also comes from database in China economic information network. The dummy variable of policy is signified as 0 before the second quarter in 2005(included) and 1 after the third quarter in 2005. D (SCF) is first difference value of SCF, and more.

\subsection{Tests for Stationarity and Johansen Co-integration Analysis}

If two or more time series are non-stationary, but a linear combination of them is stable, then the series are said to be co-integrated. The co-integration can be taken as kind of long-run equilibrium. The co-integrated variables may fluctuate in the short run, but in a long run, they can regress to their intrinsic relationship. 
A test for stationarity must be implemented to assure the time series are stationarity of the same differences before the co-integration analysis, in short, I (d). The ADF test shows that all time series in this study are I (1) at $1 \%$ significant level.

We employ the Johansen co-integration analysis to test SCF and other time series to identify the long-term relationships.

Table 1. Johansen co-integration analysis

\begin{tabular}{cllllll}
\hline \multirow{2}{*}{ variable } & \multicolumn{3}{c}{ level } & \multicolumn{3}{c}{ first difference } \\
\cline { 2 - 7 } & $(\mathrm{C}, \mathrm{T}, \mathrm{L})$ & $\begin{array}{c}\text { ADF } \\
\text { value }\end{array}$ & P value & $\begin{array}{l}(\mathrm{C}, \mathrm{T}, \\
\mathrm{L})\end{array}$ & ADF value & P value \\
\hline $\mathrm{SCF}$ & $(\mathrm{c}, \mathrm{t}, 0)$ & -3.9568 & 0.0119 & $(\mathrm{c}, \mathrm{t}, 2)$ & -6.0457 & 0.0001 \\
\hline $\mathrm{RR}$ & $(\mathrm{c}, 0,0)$ & -2.9873 & 0.0459 & $(\mathrm{c}, 0,1)$ & -8.4857 & 0.0000 \\
\hline $\mathrm{DE}$ & $(\mathrm{c}, 0,0)$ & -1.2395 & 0.6461 & $(\mathrm{c}, 0,1)$ & -7.1014 & 0.0000 \\
\hline $\mathrm{CSV}$ & $(\mathrm{c}, 0,3)$ & -1.8599 & 0.3461 & $(\mathrm{c}, 0,0)$ & -3.4645 & 0.0154 \\
\hline $\mathrm{RE}$ & $(\mathrm{c}, 0,0)$ & -0.9346 & 0.7651 & $(\mathrm{c}, 0,0)$ & -4.9965 & 0.0003 \\
\hline
\end{tabular}

Table 1 shows a co-integration equation can be deduced at $1 \%$ significant level. After normalized co-integrating coefficients, the equation is as follows:

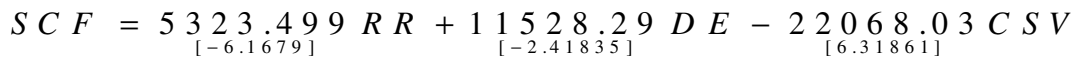

$$
\begin{aligned}
& +2 \underset{[-3.26743]}{514099 R+7987.563}
\end{aligned}
$$

The long-term relationships between short-term capital flows and the influence factors are shown in equation. T-tests are all significant. The results indicate that, RR is in line with theoretical expectations, the symbol before RR is plus, high rewards of domestic interest may attract arbitrage, and in the meanwhile, net flows of short-term capital increase. The symbol before DE, which signifies the expected exchange rate, is also plus, can explain the capital flows due to expected appreciation. The plus before RE shows that the net flows of short-term capital may increase along with ascend of the housing price. The minus before CSV shows the negative relationship between net flows and circulated stock value, which indicates the investors abroad mainly pay attention to the appreciation on real asset.

\subsection{Empirical Results}

The co-integration can be taken as kind of the long-run equilibrium. On the basis of co-integration vector, VECM model for SCF is as follows:

$$
\begin{aligned}
& \text { vecm } m_{t-1}=S C F_{t-1}-5323.499 R R_{t-1}+11528.29 D E_{t-1}+22068.03 C S V_{t-1} \\
& -2514.099 R E_{t-1}-7987.563
\end{aligned}
$$


Table 2. VECM for SCFI

\begin{tabular}{|c|c|c|c|}
\hline Error correction & $\Delta S C F I_{t}$ & Error correction & $\triangle S C F I_{t}$ \\
\hline vecm $m_{t-1}$ & $\begin{array}{c}-1.010483 \\
{[-2.35390]} \\
\end{array}$ & $\Delta D E_{t-2}$ & $\begin{array}{c}-30492.35 \\
{[-1.99344]} \\
\end{array}$ \\
\hline$\Delta S C F I_{t-1}$ & $\begin{array}{l}0.103105 \\
{[0.33340]}\end{array}$ & $\Delta C S V_{t-1}$ & $\begin{array}{c}106197.5 \\
{[2.22259]} \\
\end{array}$ \\
\hline$\Delta S C F I_{t-2}$ & $\begin{array}{c}0.302734 \\
{[1.14520]} \\
\end{array}$ & $\Delta C S V_{t-2}$ & $\begin{array}{c}152.4894 \\
{[0.00363]}\end{array}$ \\
\hline$\Delta R R_{t-1}$ & $\begin{array}{c}-4271.186 \\
{[-1.68191]}\end{array}$ & $\Delta R E_{t-1}$ & $\begin{array}{c}-3389.338 \\
{[-0.73199]}\end{array}$ \\
\hline$\Delta R R_{t-2}$ & $\begin{array}{c}-3393.388 \\
{[-1.20147]} \\
\end{array}$ & $\Delta R E_{t-2}$ & $\begin{array}{c}576.9738 \\
{[0.13439]} \\
\end{array}$ \\
\hline$\Delta D E_{t-1}$ & $\begin{array}{c}-10977.46 \\
{[-0.81861]}\end{array}$ & Policy & $\begin{array}{c}-36034.19 \\
{[-1.99784]}\end{array}$ \\
\hline$C$ & $\begin{array}{c}5067.679 \\
{[0.80402]}\end{array}$ & & \\
\hline
\end{tabular}

Note: $\triangle$ denote first difference, $[$ ] is t value

Table 2 shows VECM model for SCF. Although some individual T-tests are not significant due to insufficient data, excessive variables and weak degree of freedom, the overall results show that the selected variables are appropriate. The error correction coefficient of SCF is -1.010483 , with a significant t-value. The error correction mechanism can be illustrated in the following way: In $\mathrm{t}-1$ period, if $\mathrm{VECM}_{\mathrm{t}-1}>0$, it implies that the net flows of short-term capital in that period are more than long-run equilibrium level. Due to a negative adjustment mechanism, when $\mathrm{D}$ (SCF) diminished, the net flows reduced in t period, the net flows regress to long-run equilibrium level. If $\operatorname{VECM}_{t-1}<0$, adjustment can be similarly deduced in opposite.

\subsection{Impulse Response and Variance Decomposition}

Impulse response and variance decomposition are used to examine the dynamic relationships among the variables and analyze the influences.

Figure 2 shows the responses of SCF when affected by other factors. When affected by a positive S.D fluctuation of RR, the fluctuation will have a positive effect on SCF in the first phase, and a trivial negative effect in the second phase, then a positive effect less than that in the first stage, finally gradually steady, which imply the interest difference between America and China will induce net flows of short-term capital in the beginning, and the effect will diminish gradually in the long term. DE signifies revenue on expected exchange will also have a positive affect on SCF in the beginning, and then the signs alternate positive and negative, finally stable. A positive S.D fluctuation of CSV will induce net flows, and 
Response to Cholesky One S.D. Innovations
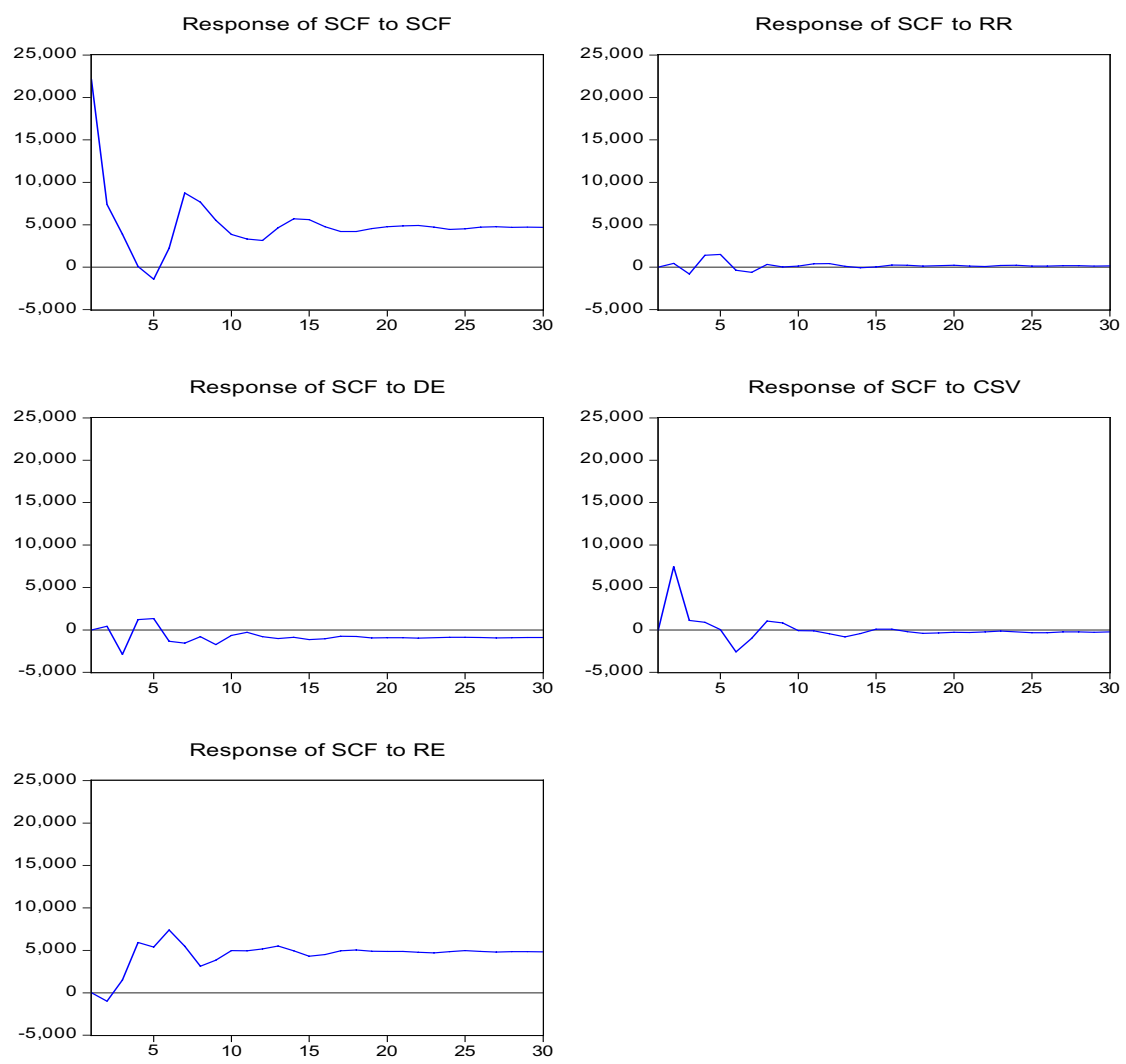

Fig. 2. Impulse Response of SCF

the effect will diminish gradually. When attacked by a positive affect by RE, the ascending assets price will induce capital outflow, then a larger outflow, finally stable.

Decomposition of variance can further analyze the dynamic character in the model.

It is a method that decomposes the variance of endogenous fluctuations into parts. The results are shown in table 3. The fluctuations of estate price account for about $27 \%$ of the S.D fluctuations in SCF; interest difference account for about $25 \%$; circulated stock value account for about $12 \%$; expected exchange rate account for about $6 \%$; itself account for others, which can be explained with inertia effect and demonstration effect. In summarize, estate price, circulated stock value, interest difference, and expected exchange rate are all factors affecting capital flows in China. 
Table 3. Variance Decomposition

\begin{tabular}{|c|c|c|c|c|c|c|}
\hline Period & S.E. & SCF & $\mathbf{R R}$ & DE & CSV & $\mathbf{R E}$ \\
\hline 1 & 22155.9 & 44.77054 & 39.75263 & 3.615741 & 11.70573 & 0.155356 \\
\hline 2 & 24541.76 & 36.80186 & 36.53518 & 3.089613 & 23.25038 & 0.322965 \\
\hline 3 & 25094.45 & 35.81934 & 35.46722 & 5.082509 & 23.01345 & 0.617487 \\
\hline 4 & 25862.51 & 33.76188 & 33.58362 & 5.068184 & 21.71653 & 5.869789 \\
\hline 5 & 26527.05 & 32.28554 & 31.93097 & 5.277863 & 20.7145 & 9.791136 \\
\hline 6 & 27783.95 & 30.6112 & 29.26959 & 5.226298 & 19.21132 & 15.68159 \\
\hline 7 & 29696.29 & 31.74517 & 28.48274 & 5.795558 & 17.30931 & 16.66721 \\
\hline 8 & 30852.93 & 31.53333 & 29.07664 & 5.869653 & 17.22657 & 16.29381 \\
\hline 9 & 31632.74 & 30.99378 & 28.88132 & 6.329609 & 16.96647 & 16.82882 \\
\hline 10 & 32256.89 & 30.51549 & 28.38028 & 6.262848 & 16.44116 & 18.40022 \\
\hline 11 & 32801.26 & 29.99504 & 27.97288 & 6.122794 & 15.97241 & 19.93688 \\
\hline 12 & 33367.79 & 29.42716 & 27.51086 & 6.074669 & 15.45371 & 21.5336 \\
\hline 13 & 34160.15 & 29.15266 & 27.02668 & 6.094267 & 14.78852 & 22.93788 \\
\hline 14 & 34995.06 & 29.17387 & 26.77683 & 6.116053 & 14.2732 & 23.66005 \\
\hline 15 & 35718.43 & 29.07358 & 26.6942 & 6.23961 & 13.96468 & 24.02793 \\
\hline 16 & 36329.85 & 28.8075 & 26.57677 & 6.302436 & 13.6708 & 24.64249 \\
\hline 17 & 36909.69 & 28.52537 & 26.33351 & 6.266014 & 13.33292 & 25.54218 \\
\hline 18 & 37496.01 & 28.30165 & 26.0506 & 6.236245 & 12.98428 & 26.42723 \\
\hline 19 & 38100.13 & 28.11432 & 25.84793 & 6.251238 & 12.65604 & 27.13047 \\
\hline 20 & 38714.22 & 27.94418 & 25.69906 & 6.264335 & 12.35328 & 27.73914 \\
\hline
\end{tabular}

Cholesky Ordering: RR DE CSV RE SCF

\section{Conclusions}

Summing up the results of the empirical test, and taking the China's short-term capital movement characteristics and financial system into consideration, we conclude as follows:

First of all, net flows of short-term capital are affected by factors such as real interest difference, expected exchange rate, and estate price, which are all labile, rather than fundamental economic factors. We once introduced variable GDP to reflect the fundamental economic (including fundamental facility construction, the quality and quantity of labors, and market prospects) in the model, which induce a remarkable ascending in AIC and SC. The result indicated that short-term capital in China is accompanied with arbitrage and speculation.

Secondly, the fluctuations of stock market and housing are the most important determinants in net flows of short-term capital. The fluctuations of stock market are determinants, which reflect the arbitrage intention of short-term capital flows. But the 
relationship between stock market and net flows is complex. Once the stock market achieved high enough, the risk increased, and short-term capital may flow out, which has indicated as a negative relationship in co-integration equation. The capital flows are also affected by the estate price, which have also shown in impulse response and variance decomposition. The fluctuations of estate price account for about $27 \%$ of the S.D fluctuations in SCF, which indicated the capital flows speculating on housing. These flows helped in pushing the ascending of housing in China.

Thirdly, the expectation on the CNY appreciation is an important factor affecting net flows of short-term capital. The impact of expected exchange rate on net flows is about $25 \%$ in variance decomposition. There is a stable long term positive relationship between the expected exchange rate and capital flows. The effect of expected exchange rate is only about $6 \%$ in VECM, which is not large enough. But in considerate of the pressure from real interest difference, the effect may be larger.

In general, short-term capital flow mechanisms are complex. There has been a surge in capital flow to China in order to speculation on interest, exchange rate, securities and asset price. In this circumstance, strict supervision and control on the fluctuations of exchange rate, as well as improvements in the CNY exchange rate regime are in need. The government should also strength risk management in stock market; stabilize housing market; further improve monitor on short-term capital flow; take precautions against financial risks promptly; properly liberalize capital account prudently.

\section{Acknowledgement}

This work is funded by NSFC (grant No.:70673100, 70621001) and Graduate University of Chinese Academy of Sciences.

\section{References}

1. Schadler, S., Carkovic, M., Bennett, A., Khan, R.: Recent Experiences with Surges in Capital Inflows, IMF Occasional Paper no. 108, Washington DC (1993)

2. Chuhan, P., Claessens, S., Mamingi, N.: Equity and Bond Flows to Asia and Latin America. IMF Working Paper 1160 (1993)

3. Baek, I.-M.: Portfolio investment flows to Asia and Latin America: pull, push or market sentiment. Journal of Asian Economics 17, 363-373 (2006)

4. Wang, Y.: Research on China's capital flow since1994. International Financial Research 6, 67-73 (2004)

5. Wang, Q.: Econometric studies on determinants of capital movement in China. International Financial Research 6, 64-69 (2006)

6. Liu, L.D.: Research on capital inflows in China. Financial Research 3, 62-70 (2007)

7. Jiang, L.Q.: Cause, infection, and prevention of international short-term capital flows. Shanghai Financial Transaction 4, 5-6 (1997)

8. Wang, X.: Cause of short-term capital inflows. International Financial Research 1, 59-64 (2003)

9. Liu, H.H., Wen, T.: Short-term capital inflows: Causes and policy proposal. Zhongnan University of Economics and Law Transaction 6, 122-130 (2005)

10. Zhang, Y.H., Pei, P., Fang, X.M.: Short-term capital inflows and triple- arbitrage model based on interest rate, exchange rate and assets price. International Financial Research 9, 41-52 (2007)

11. Lan, Z.H., Chen, L.: The scale of Short-term capital flows and Econometric studies. Financial Economic 4, 48-49 (2007) 